\title{
PENGENALAN POLA HURUF HIJAIYAH KHAT KUFI DENGAN METODE DETEKSI TEPI SOBEL BERBASIS JARINGAN SYARAF TIRUAN BACKPROPAGATION
}

\author{
Irvan Faturrahman ${ }^{1}$, Arini $^{2}$, Fitri Mintarsih ${ }^{3}$ \\ ${ }^{1,2,3}$ Program Studi Teknik Informatika, Fakultas Sains dan Teknologi \\ Universitas Islam Negeri Syarif Hidayatullah Jakarta \\ irvanfaturr1@gmail.com,arini@uinjkt.ac.id,mintarsihf@gmail.com
}

\begin{abstract}
ABSTRAK
Khat kufi memiliki bentuk huruf hijaiyah yang unik berbentuk kotak. Banyak penelitian yang membahas pengenalan huruf hijaiyah namun untuk spesifik khat belum ada. Pada penelitian ini penulis melakukan simulasi pengenalan pola huruf hijaiyah khat kufi menggunakan deteksi tepi sobel dan jaringan syaraf tiruan backpropagation dengan menggunakan parameter uji learning rate dan epoch. Simulasi dilakukan 28 target huruf hijaiyah dengan learning rate $0.01,0.05,0.1,0.5$, dan epoch $25,1000,3000,5000,10000$. Akurasi terbaik didapatkan pada learning rate 0.01 dan epoch 10000 yaitu $100 \%$. Penelitian ini dapat dikembangkan menggunakan deteksi tepi canny, prewitt, atau robert serta JST $L V Q, A D A L I N E$, atau $R B F$.
\end{abstract}

Kata Kunci: Khat Kufi, Deteksi Tepi Sobel, Jaringan Syaraf Tiruan Backpropagation, Simulasi

\begin{abstract}
Khat kufi has a unique hijaiyah shape that is square in shape. Much of the research that discusses the introduction of the hijaiyah letters but for the specifics khat does not yet exist. In this study, the author performs a simulation of hijaiyah khat kufi pattern recognition using sobel edge detection and artificial neural network backpropagation using learning rate test and epoch parameters. The simulation has been done on 28 target letters hijaiyah with learning rate $0.01,0.05,0.1,0.5$, and epoch 25, 1000, $3000,5000,10000$. The best accuracy obtained at learning rate 0.01 and epoch 10000 is $100 \%$. This research can be developed using canny edge detection, prewitt, or robert and also JST LVQ, ADALINE, or RBF.
\end{abstract}

Keywords: Khat Kufi, Detection Of Sobel Edge, Backpropagation Artificial Neural Networks, Simulation

DOI : 10.15408/jti.v11i1.6262 


\section{PENDAHULUAN}

\subsection{Latar Belakang}

Seni kaligrafi yang merupakan kebesaran seni Islam, lahir di tengah-tengah dunia arsitektur dengan segar bugar. Ini dapat dibuktikan pada aneka ragam hiasan kaligrafi yang memenuhi masjid-masjid dan bangunanbangunan lainnya, yang ditumpahkan dalam paduan ayat-ayat al-Qur'an yang mulia, haditshadits atau kata-kata hikmat para ulama bijaksana. Kaligrafi sendiri mempunyai jenisnya masing-masing, salah satunya adalah khat kufi. Khat kufi merupakan khat yang paling tua di antara teman-temannya. Selain karena usianya, kaligrafi ini terkenal dengan bentuknya yang kotak-kotak. Karenanya, kaligrafi ini cukup mudah digoreskan jika ada mistar di sisi kita. Kufi merupakan salah satu khat paling populer untuk dekorasi masjid. Karena bentuknya yang kotak-kotak khat kufi sangat mudah dibedakan dalam penulisan dengan khat lainnya [1].

Kaligrafi sendiri biasanya ditulis tangan oleh seseorang yang bisa disebut dengan khatat. Setiap khatat mempunyai teknik tersendiri dalam menulisakan kaligrafi. Namun untuk dapat membaca sebuah kaligrafi seseorang perlu memahami bentuk dari masing-masing huruf hijaiyah terlebih dahulu. Menurut Ketua UKM Lemka UIN Syarif Hidayatullah periode 20142016, Mochammad Sholeh, walaupun seseorang telah mengetahui bagaimana bentuk dan pola dari huruf hijaiyah yang ditulis dengan gaya biasa seperti yang ada dalam al-Qur'an sekarang ini, tetap saja akan sulit untuk membaca sebuah tulisan kaligrafi. Oleh karena itu kita harus memahami betul bagaimana bentuk dan pola huruf hijaiyah dengan spesifik khat, disini peneliti menggunakan khat kufi. Sebab jika tidak bisa mengenali huruf hijaiyah maka akan sulit untuk membacanya. Untuk khat kufi sendiri memiliki bentuk huruf hijaiyah yang hampir sama dan unik satu dengan yang lainnya. Biasanya orang hanya mengira-ngira huruf hijaiyah tersebut. Sehingga perlu suatu program yang dapat mengenali huruf hijaiyah dengan khat kufi. Program tersebut difungsikan untuk mengenali karakter huruf hijaiyah dengan khat kufi yang kemudian memberikan solusi bagi mesin untuk dapat mengenalinya.

Pada penelitian ini peneliti melakukan pengenalan pola huruf hijaiyah khat kufi dengan menggunakan jaringan syaraf tiruan algoritma backpropagation. Peneliti menggunakan algoritma backpropagation karena algoritma backpropagation termasuk ke dalam lapisan terawasi (supervised) yang mana terdapat sepasang data (masukan-target-keluaran) yang dipakai untuk melatih bobot yang diinginkan, dan algoritma backpropagation mampu mengenali pola yang akan digunakan selama pelatihan serta kemampuan jaringan untuk memberikan respon yang benar terhadap pola masukan yang serupa (tapi tidak sama) dengan pola yang dipakai selama pelatihan [2].

Peneliti juga menggunakan teknik operasi pengolahan citra, yaitu deteksi tepi. Deteksi tepi sangat penting dalam pengolahan citra karena pendeteksian tepi melingkupi informasi di dalam citra. Dimana, tepi memberikan batas-batas objek citra. Tujuan operasi pendeteksian tepi adalah untuk meningkatkan penampakan garis batas suatu daerah atau objek di dalam citra. Ada banyak metode pendeteksian tepi, salah satunya adalah sobel. Sobel merupakan salah satu metode deteksi tepi yang memiliki kelebihan yaitu kemampuan untuk mengurangi noise sebelum melakukan perhitungan deteksi [3].

Sebelumnya telah banyak penelitian mengenai pengolahan citra pada pengenalan pola menggunakan jaringan syaraf tiruan backpropagation diantaranya penelitian yang dilakukan oleh [4], [5], [6], dan [7]. Semua penelitian tersebut melakukan pengenalan pola huruf seperti huruf hijaiyah dan huruf aksara Lampung serta identifikasi jenis kaligrafi yang memberikan hasil cukup optimal dalam pengenalan pola. Namun untuk penelitian mengenai pengenalan pola huruf hijaiyah dengan spesifik khat dengan kombinasi jaringan syaraf tiruan backpropagation dan deteksi tepi sobel belum pernah dilakukan sebelumnya sehingga peneliti tertarik untuk melakukan penelitian mengenai pengenalan pola huruf hijaiyah dengan khat kufi.

Berdasarkan latar belakang tersebut peneliti ingin melakukan sebuah pengenalan pola huruf hijaiyah khat kufi dan menjadikannya sebagai bahan kajian yang dituangkan dalam bentuk penelitian dengan judul "Pengenalan Pola Huruf Hijaiyah Khat Kufi dengan Metode Deteksi Tepi Sobel Berbasis Jaringan Syaraf Tiruan Backpropagation".

\subsection{Rumusan Masalah}

Berdasarkan latar belakang yang telah diuraikan sebelumnya, rumusan masalah yang akan diangkat dalam penelitian ini adalah bagaimana menerapkan metode jaringan syaraf 
tiruan backpropagation dan deteksi tepi sobel untuk mengenali pola huruf hijaiyah khat kufi.

\subsection{Batasan Masalah}

Pada penelitian ini untuk lebih memusatkan masalah yang ada agar tidak menyimpang dari topik maka batasan masalah hanya akan membahas:

1. Penelitian ini hanya membahas pengenalan pola satu jenis khat yaitu khat kufi.

2. Citra input berupa 28 huruf hijaiyah khat kufi dua dimensi hasil scan dan jenis font shafa menggunakan software Nonosoft Khot dengan posisi citra tegak dan arah penulisan horisontal.

3. Pengolahan citra yang digunakan dalam penelitian adalah scaling, grayscale, deteksi tepi sobel, thresholding, dan dilasi.

4. Proses pengenalan pola menggunakan jaringan syaraf tiruan backpropagation dengan menggunakan skenario dari nilai learning rate dan jumlah epoch sebagai parameter pelatihan.

5. Dalam penelitian ini perangkat keras yang digunakan hanya berupa laptop sebagai media untuk perancangan software Matlab dan pengujian sistem.

6. Output dari penelitian ini menghasilkan simulasi pengenalan pola huruf hijaiyah khat kufi.

\section{LANDASAN TEORI}

\subsection{Khat Kufi}

Kufi termasuk tulisan paling dominan pada zaman dahulu. Ia dibuat setelah berdirinya dua kota muslim yaitu Basrah dan Kufah pada dekade kedua era Islam sekitar abad ke-8 Masehi. Ia memiliki bentuk huruf yang proporsional kaku dan persegi. Dari kata Kufah maka tulisan ini dikenal dengan Kufi. Ciri pokok tulisan kufi sangat jelas, yakni berukuran seimbang yang spesifik dengan sifat bersudutsudut atau persegi menyolok, memiliki sapuansapuan garis vertikal pendek dan garis-garis horizontal yang memanjang dalam ukuran sama lebar. Akan tampak bahwa tulisan berbentuk empat persegi panjang. Dalam gaya hias atau iluminasi, ukuran tersebut terkadang tidak mengikat betul. Misalnya, pada sapuan garis vertikal yang dibikin panjang-panjang melebihi garis-garis horisontalnya. Namun tetap harus ditekankan, bahwa tulisan kufi adalah tulisan bersiku-siku [1].

\subsection{Pengenalan Pola}

Secara umum pengenalan pola adalah suatu ilmu untuk mengklasifikasikan atau menggambarkan sesuatu berdasarkan pengukuran kuantitatif fitur (ciri) atau sifat utama dari suatu objek. Pola bisa merupakan kumpulan hasil pengukuran atau pemantauan dan bisa dinyatakan dalam notasi vektor atau matriks [3].

\subsection{Deteksi Tepi Sobel}

Operator sobel adalah salah satu operator yang menghindari adanya perhitungan gradien di titik interpolasi. Operator sobel menggunakan 2 matriks berukuran 3x3 yaitu matriks Gx dan Gy. Kedua matriks tersebut digunakan untuk menghitung perbedaan warna pada piksel yang sedang dihitung dengan piksel di sekitarnya secara horisontal dan vertikal. Matriks Gx digunakan untuk menghitung secara horisontal dan matriks Gy secara vertikal [8].

\begin{tabular}{|l|l|l|}
\hline-1 & 0 & +1 \\
\hline-2 & 0 & +2 \\
\hline-1 & 0 & +1 \\
\hline
\end{tabular}

Gx

\begin{tabular}{|c|c|c|}
\hline+1 & +2 & +1 \\
\hline 0 & 0 & 0 \\
\hline-1 & -2 & -1 \\
\hline
\end{tabular}

Gy
Gambar 1. Matriks metode Sobel

\subsection{Jaringan Syaraf Tiruan}

Menurut Fausett dalam [9], jaringan syaraf tiruan adalah generalisasi dari pemodelan syaraf biologi dengan asumsi-asumsi antara lain:

1. Pemrosesan informasi terletak pada sejumlah komponen yang dinamakan neuron.

2. Sinyal merambat antara satu neuron ke neuron-neuron lainnya melalui jalur penghubung.

3. Tiap jalur penghubung memiliki bobot dan mengalikan besar nilai sinyal yang masuk (jenis neuron tertentu).

4. Tiap neuron menerapkan fungsi aktivasi (biasanya nonlinear) yang menjumlahkan semua masukan untuk menentukan sinyal keluarannya.

5. Tiap jaringan ditentukan oleh arsitektur pola jaringan, bobot pada koneksi dan fungsi aktivasi. 


\subsection{Jaringan Syaraf Tiruan Backpropagation}

Backpropagation merupakan salah satu algoritma pelatihan terawasi. Algoritma ini biasa digunakan untuk mengubah bobot-bobot yang terhubung dengan neuron-neuron yang ada pada lapisan tersembunyinya. Backpropagation menggunakan error output untuk mengubah nilai bobot-bobotnya dalam arah mundur (backward).

Backpropagation memiliki beberapa unit yang ada dalam satu atau lebih layer tersembunyi. Gambar 2 di bawah ini merupakan arsitektur backpropagation dengan $\mathrm{n}$ buah masukan (ditambah sebuah bias), sebuah layer tersembunyi yang terdiri dari $\mathrm{p}$ unit (ditambah sebuah bias), serta m buah unit keluaran [2].

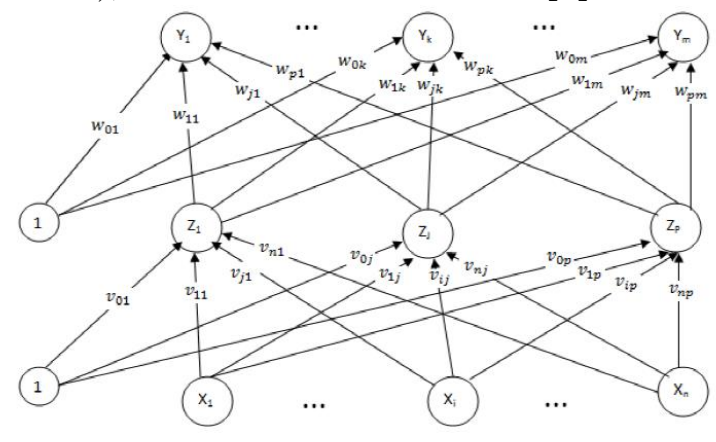

Gambar 2. Proses backpropagtion

Algoritma backpropagation untuk pelatihan dengan jaringan satu layer tersembunyi (menggunakan fungsi aktivasi sigmoid biner) adalah sebagai berikut:

Langkah 0: Inisialisasi semua bobot dengan bilangan acak kecil.

Langkah 1: Jika kondisi penghentian belum terpenuhi, lakukan langkah 2-9.

Fase I: Propagasi maju

Langkah 2: Untuk setiap pasang data pelatihan, lakukan langkah 3-8.

Langkah 3: Tiap unit masukan menerima sinyal dan meneruskannya ke unit tersembunyi di atasnya.

Langakah 4: Hitung semua keluaran unit tersembunyi $\mathrm{z}_{\mathrm{j}}$

$(j=1,2, \ldots ., p)$.

$z_{-} n e t_{j}=v_{j 0}+\sum_{i=1}^{n} x_{i} v_{i j}$

$z_{j}=f\left(z_{\text {net } j}\right)=\frac{1}{1+e^{-y_{-1 e t}}}$

Langkah 5: Hitung semua keluaran jaringan di unit $\mathrm{y}_{\mathrm{k}}$.

$(\mathrm{k}=1,2, \ldots, \mathrm{m})$.

$y_{-}$net $_{k}=w_{k 0}+\sum_{j=1}^{p} z_{j} w_{k j}$ $y_{k}=f\left(y_{-n e t k}\right)=\frac{1}{1+e^{-y_{-} \text {net }_{k}}}$

Fase II: Propagasi Mundur

Langkah 6: Hitung faktor $\delta$ unit keluaran berdasarkan kesalahan di setiap unit keluaran $\mathrm{y}_{\mathrm{k}}(\mathrm{k}=1,2, \ldots, \mathrm{m})$.

$\delta_{k}=\left(t_{k}-y_{k}\right) f^{\prime}\left(y_{n e t_{k}}\right)=\left(t_{k}-y_{k}\right) y_{k}\left(1-y_{k}\right)$

$\delta_{\mathrm{k}}$ merupakan unit kesalahan yang akan dipakai dalam perubahan bobot layer dibawahnya (langkah 7).

Hitung suku perubahan bobot $\mathrm{w}_{\mathrm{kj}}$ (yang akan dipakai nanti untuk merubah bobot $\mathrm{w}_{\mathrm{kj}}$ ) dengan laju percepatan $\alpha$.

$\Delta w_{k j}=\alpha \delta_{k} z_{j j} ; \mathrm{k}=1,2, \ldots, \mathrm{n} ; \mathrm{j}=0,1, \ldots ., \mathrm{p}$

Langkah 7: Hitung faktor $\delta$ unit tersembunyi berdasarkan kesalahan di setiap unit tersembunyi $\mathrm{z}_{\mathrm{j}}(\mathrm{j}-1,2, \ldots ., \mathrm{p})$.

$\delta_{-} n e t_{j}=\sum_{k=1}^{m} \delta_{k} w_{k j}$

Faktor $\delta$ unit tersembunyi:

$\delta_{j}=\delta_{-}$net $_{j} f^{s}\left(z_{\text {net }}\right)=\delta_{\text {net }} z_{j}\left(1-z_{j}\right)$

Hitung suku perubahan bobot vij (yang akan dipakai nanti untuk merubah bobot vij).

$\Delta v_{k j}=\alpha \delta_{i} x_{i} ; \mathrm{j}=1,2, \ldots ., \mathrm{p} ; \mathrm{i}=0,1, \ldots ., \mathrm{n}$

Fase III: Perubahan Bobot

Langkah 8: Hitung semua perubahan bobot.

Perubahan bobot garis yang menuju ke unit keluaran

$w_{k j}($ baru $)=w_{k j}($ lama $)+\Delta w_{k j}$

$(\mathrm{k}=1,2, \ldots ., \mathrm{m} ; \mathrm{j}=0,1, \ldots ., \mathrm{p})$

Perubahan bobot garis yang menuju ke unit tersembunyi

$v_{j i}($ baru $)=v_{j i}($ lama $)+\Delta v_{j i}$

$(j=1,2, \ldots ., p ; i=0,1, \ldots ., n)$

\subsection{Metode Simulasi}

Konsep sistem simulasi muncul dan dilaksanakan pada permulaan tahun 1950-an. Konsep ini muncul sebagai akibat dari terjadinya berbagai perubahan di dalam memandang persoalan, dimana suatu persoalan dianggap dapat diuraikan menurut bagian-bagian yang berinteraksi secara simultan. Perubahan-perubahan semacam ini secara nyata dapat diamati dalam percobaan. Sistem simulasi memberikan hasil yang layak (feasible) pada EDP, dimana hasilnya dapat diperoleh dengan cepat. Simulasi juga memberikan kemungkinan untuk mengerjakan seluruh bagian dalam sistem analisis yang sebenarnya merupakan persoalan yang kompleks yang harus dikerjakan dengan analisis [10]. Tahapan simulasi sebagai berikut. 
1. Formulasi Permasalahan (Problem Formulation)

2. Pemodelan Formulasi (Modelling Formulation)

3. Persiapan Pengambilan Data (Data Preparation)

4. Penulisan Program (Write Program)

5. Verifikasi dan Validasi (Verification and Validation)

6. Desain Eksperimen (Experimental Design)

7. Perencanaan Taktis (Tactical Planning)

8. Pelaksanaan Percobaan (Experiment Done)

9. Model Terpakai (Useful Model)

10. Dokumentasi (Documentation)

\section{METODOLOGI PENELITIAN}

\subsection{Metode Pengumpulan Data}

Tahapan pengumpulan data yang digunakan dalam penelitian adalah sebagai berikut:

1. Studi Pustaka dan Literatur Sejenis

2. Wawancara

\subsection{Metode Simulasi}

1. Problem Formulation

Pada tahap ini penulis mengumpulkan data dan menganalisis masalah dari hasil studi pustaka dan wawancara.

2. Modelling Formulation

Setelah permasalahan dirumuskan, selanjutnya dibuat pemodelan yang akan digunakan untuk melakukan simulasi pelatihan dan identifikasi pola huruf hijaiyah menggunakan jaringan syaraf tiruan backpropagation dengan diawali praproses citra menggunakan deteksi tepi sobel.

3. Data Preparation

Langkah selanjutnya yaitu menentukan input yang akan di proses dan output yang akan didapat.

4. Write Program

Tahap selanjutnya yaitu pengkodean. Pada tahap ini, aplikasi yang akan digunakan untuk simulasi dibuat dengan MATLAB (Matrix Laboratory) sesuai pemodelan yang dibuat pada tahap kedua.

5. Verification and Validation

Selanjutnya memeriksa kesesuaian program dengan simulasi yang diinginkan. Selain itu, dilakukan debugging dan perbaikan berupa pengeditan pada program. Jika program yang dibuat dapat berjalan di komputer, maka akan dilanjutkan dengan tahap berikutnya.

6. Experimental Design

Desain eksperimen menjelaskan bagaimana data input didapatkan untuk pelaksanaan percobaan pada model. Dalam hal ini sampel huruf hijaiyah khat kufi.

7. Tactical Planning

Dalam perencanaan ini dibutuhkan pemeriksaan kembali terhadap hasil dari tahap desain eksperimen. Pemeriksaan dilakukan dengan menyesuaikan sampel yang telah disediakan dengan hasil sampel huruf hijaiyah yang seharusnya.

8. Experiment Done

Penulis melakukan percobaan dengan memasukkan data input pada program yang telah dibuat dan lolos tahap verifikasi. Jika hasil percobaan sesuai kebutuhan penulis, maka program tersebut dapat digunakan sebagai model.

9. Useful Model

Model yang telah selesai dilakukan percobaan untuk memeriksa kesesuaian program yang dibuat dengan model yang diinginkan, selanjutnya digunakan untuk mendapatkan data yang digunakan penulis untuk dianalisis tingkat akurasi.

10. Documentation

Langkah ini dilakukan dengan merekam program yang telah dibuat menjadi model simulasi dan mendokumentasikan hasil analisis ke dalam sebuah laporan. 


\subsection{Kerangka Berpikir}

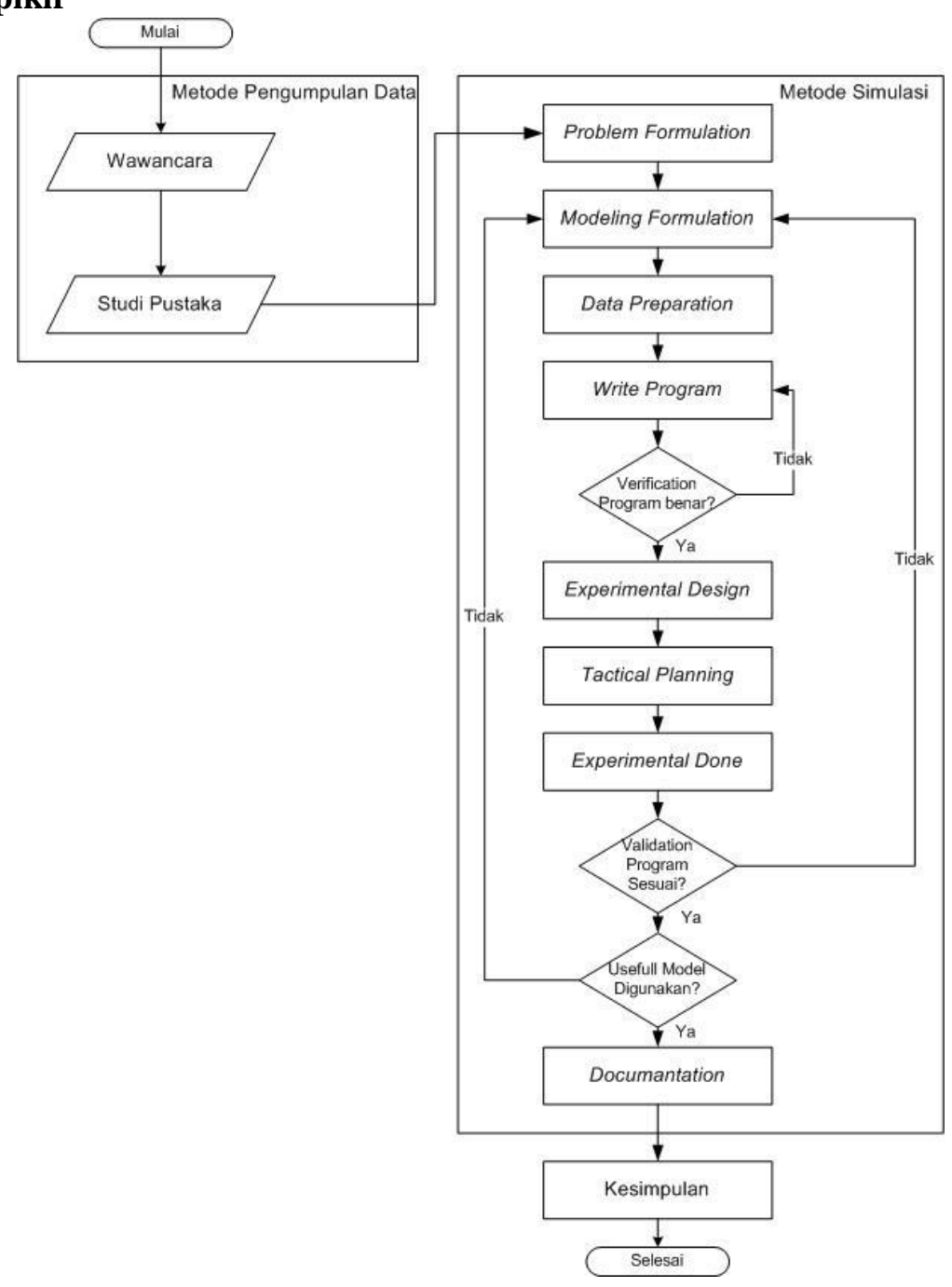

Gambar 3. Kerangka pemikiran

\section{IMPLEMENTASI SIMULASI DAN EKSPERIMEN}

\subsection{Problem Formulation}

Berdasarkan permasalahan yang telah dipaparkan sebelumnya, penulis menerapkan gabungan dari salah satu metode pengolahan citra dan jaringan syaraf tiruan yaitu, deteksi tepi sobel dan jaringan syaraf tiruan backpropagation. Penerapan ini diharapkan dapat menghasilkan proses pembelajaran pada sistem menggunakan jaringan syaraf tiruan backpropagation yang nantinya akan memberikan hasil pengenalan pola huruf hijaiyah khatkufi.

Pada penelitian ini, masalah yang harus diselesaikan adalah bagaimana menerapkan metode jaringan syaraf tiruan backpropagation dan deteksi tepi sobel untuk mengenali pola huruf hijaiyah khat kufi. Penulis akan melakukan simulasi pada sistem yang telah dibuat dengan parameter pengaruh hasil jaringan, learning rate, maksimal epoch terhadap akurasi pengenalan.

\subsection{Modelling Formulation}

Simulasi sistem dibuat berdasarkan pemodelan yang dirancang pada tahap ini. Sistem dibuat untuk dapat menjalankan tahap pelatihan dan identifikasi dari metode jaringan syaraf tiruan backpropagation. 


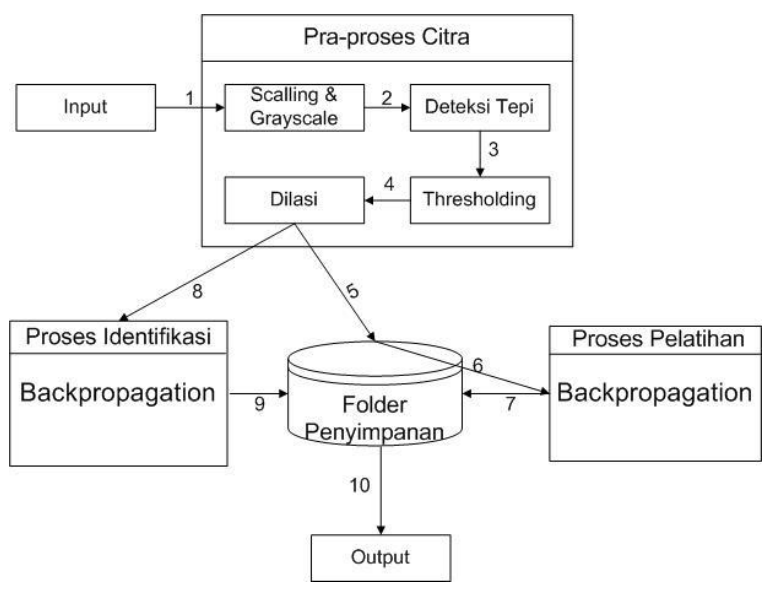

Gambar 4. Gambaran umum pengenalan pola huruf

\subsection{Data Preparation}

Simulasi berjalan dengan skenario simulasi berikut:

Tabel 1. Skenario simulasi

\begin{tabular}{ccccc}
\hline \multicolumn{4}{c}{ Tabel 1. Skenario simulasi } \\
\hline $\begin{array}{c}\text { Indikator } \\
\text { Penilaian }\end{array}$ & Skenario & $\begin{array}{c}\text { Jumlah } \\
\text { Epoch }\end{array}$ & $\begin{array}{c}\text { Nilai } \\
\text { Learning } \\
\text { Rate }\end{array}$ & Keterangan \\
\hline $\begin{array}{c}\text { Pengaruh } \\
\text { Nilai } \\
\text { Learning } \\
\text { Rate }\end{array}$ & LR1 & 25 & 0.01 & $\begin{array}{c}\text { Nilai } \\
\text { Default }\end{array}$ \\
\cline { 2 - 5 } & LR2 & 25 & 0.05 & \\
\cline { 2 - 5 } & LR3 & 25 & 0.1 & \\
\hline Pengaruh & ER4 & 25 & 0.5 & \\
\cline { 2 - 5 } $\begin{array}{c}\text { Jumlah } \\
\text { Epoch }\end{array}$ & E2 & 1000 & 0.01 & \\
\cline { 2 - 5 } & E3 & 5000 & 0.01 & \\
\cline { 2 - 5 } & E4 & 10000 & 0.01 & \\
\hline
\end{tabular}

\section{HASIL DAN PEMBAHASAN}

\subsection{Verification and Validation}

Verifikasi dan validasi dilakukan dengan memeriksa kesesuaian program yang telah dibuat dengan hasil dari debugging program pada komputer.
1. Pra Proses Citra

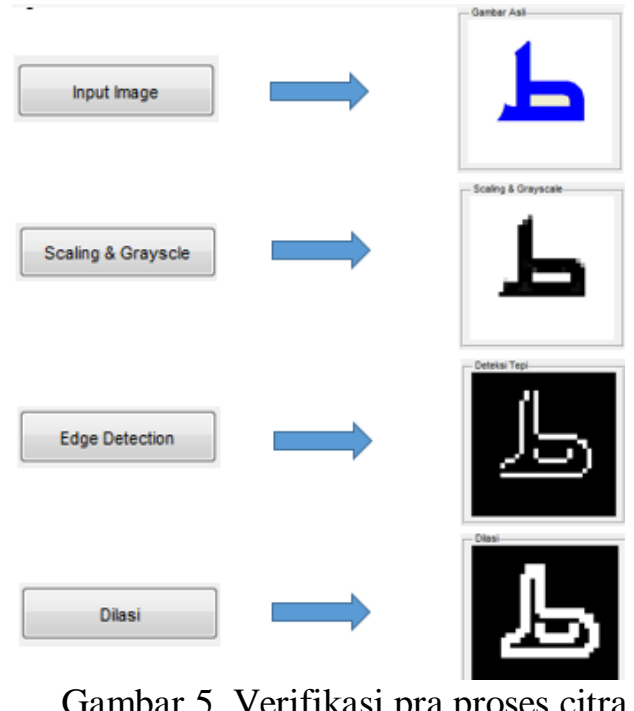

2. Pelatihan
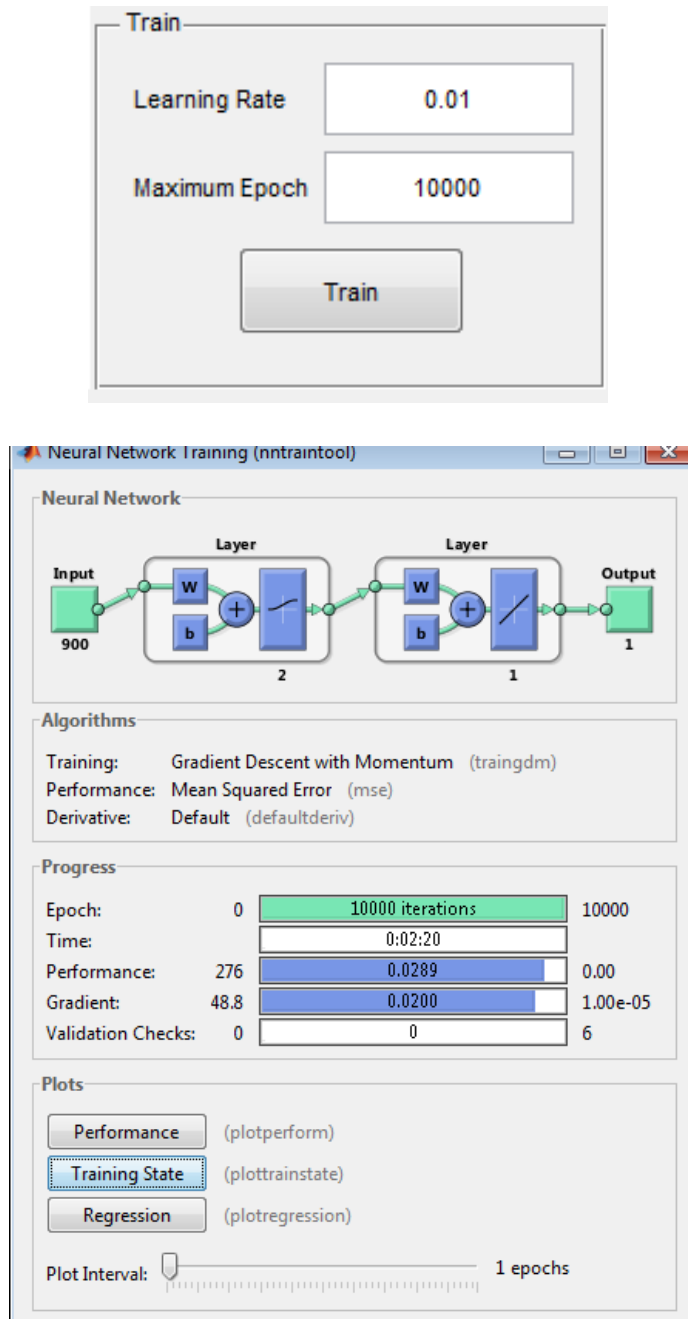

Gambar 6. Verifikasi pelatihan 
3. Identifikasi

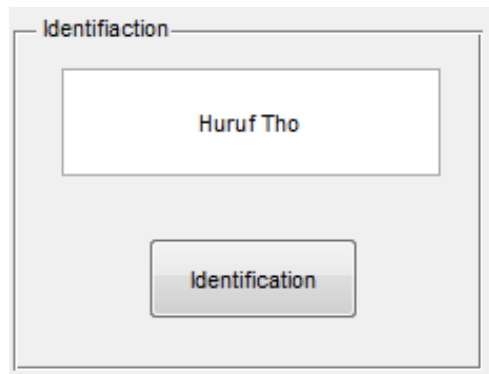

Gambar 7. Verifikasi identifikasi

\subsection{Experimental Design}

Data simulasi yang digunakan berukuran 300x300 piksel menggunakan tools Adobe Photoshop. Data terbagi menjadi dua, yaitu data latih dan data uji. Data latih untuk simulasi ini terdiri dari dua sampel pada masing-masing huruf hijaiyah tersebut. Untuk data uji, citra hijaiyah khatkufi diambil dari hasil tulisan tangan anggota UKM Lemka UIN Syarif Hidayatullah Jakarta (Ahmad Kusairi) dan font huruf shafa pada software Nonosoft Khot. Data uji juga dibuat berukuran $300 \times 300$ piksel yang nantinya akan di resize oleh sistem pada tahap scaling hingga berukuran 30 x 30 piksel. Sama dengan data latih, data uji untuk 28 pola huruf hijaiyah terdiri dari dua sampel terhadap masing-masing huruf hijaiyah.

\subsection{Tactical Planning}

Simulasi dilakukan pada 28 huruf hijaiyah khat kufi. Masing-masing huruf hijaiyah dibutuhkan dua sampel sebagai data latih. Sehingga perhitungan jumlah data sampel yang dibutuhkan sebagai data latih dan data uji pada simulasi ini.

\subsection{Experiment Done}

Percobaan dilakukan setelah model dapat berfungsi sesuai dengan model yang telah dirancang. Pemeriksaan fungsi pada program yang telah berhasil di-debug dengan memasukkan jumlah epoch dan nilai learning rate untuk pelatihan dan mengidentifikasi citra yang dimasukkan sesuai hasil jaringan yang telah dilatih.

\subsection{Useful Model}

Pada tahap ini dilakukan skenario simulasi sesuai dengan data preparation yang telah diberikan sebelumnya kemudian hasilnya dirangkum dalam tahap dokumentasi.

\subsection{Documentation}

Setelah dilakukan pengujian berdasarkan skenario yang sebelumnya terhadap sampelsampel citra huruf hijaiyah khat kufi, maka didapat hasil sebagai berikut.

Tabel 2 Tingkat akurasi hasil uji coba skenario

\begin{tabular}{clllll}
\hline No & Skenario & Akurasi & No & Skenario & Akurasi \\
\hline 1 & LR1 & $3,57 \%$ & 5 & E1 & $56,25 \%$ \\
2 & LR2 & $3,57 \%$ & 6 & E2 & $81,25 \%$ \\
3 & LR3 & $3,57 \%$ & 7 & E3 & $94,64 \%$ \\
4 & LR4 & $3,57 \%$ & 8 & E4 & $100 \%$ \\
\hline
\end{tabular}

Hasil rangkuman pada Tabel 2 terlihat bahwa skenario E4 memiliki nilai akurasi tertinggi yaitu mencapai $100 \%$. Pada tabel tersebut juga terlihat bahwa skenario LR1, LR2, LR3, dan LR4 memiliki akurasi paling kecil jika dibandingkan dengan skenario epoch. Hal itu disebabkan oleh beberapa faktor, diantaranya yaitu:

1. Pengaruh perbedaan masing-masing sampel

Pada penelitian menggunakan dua sampel berbeda dengan masing-masing sampel diberikan satu sampel lain untuk melihat perbedaan hasil backpropagation-nya. Terlihat sedikit perbedaan pada sampel yang sama sehingga nilai output pelatihan dan output identifikasi hampir mendekati satu dengan yang lain

2. Pengaruh pengolahan

Tahap scaling pada pengolahan citra (praproses) dan identifikasi akan menentukan akurasi sistem. Semakin besar ukuran citra huruf yang digunakan maka waktu komputasi sistem akan semakin lama. Namun jika terlalu kecil ukuran citra huruf maka matriks sobel di dalamnya akan bernilai hampir sama antara citra satu dengan yang lainnya. Sehingga diperlukan resizing yang tidak terlalu besar dan juga terlalu kecil. Dan skala resize yang digunakan dalam penelitian ini adalah 0.1.

3. Pengaruh parameter pelatihan

Ada beberapa parameter-parameter jaringan syaraf tiruan algoritma backpropagation yang digunakan dalam penelitian ini yaitu:

\footnotetext{
- net.trainParam.lr =

LearningRate;
}

Digunakan untuk menentukan laju pemahaman $(\alpha)$. Semakin besar laju pemahaman maka semakin cepat pelatihannya. Tetapi semakin besar 
nilai laju pemahamannya maka algoritma menjadi semakin tidak stabil dan akurasinya rendah.

- net.trainParam.epochs

Epoch;

Digunakan untuk menentukan jumlah maksimum epoch pelatihan (iterasi). Pada penelitian ini semakin besar jumlah epoch maka proses pelatihan membutuhkan waktu yang lama tapi menghasilkan tingkat akurasi yang cukup tinggi. Namun sebaliknya semakin kecil jumlah epoch maka proses pelatihan membutuhkan waktu yang relatif singkat tapi menghasilkan tingkat akurasi yang rendah.

- net.trainParam.goal = 0 ;

Digunakan untuk menentukan batas nilai MSE agar iterasi dihentikan. Proses pelatihan akan berhenti juga nilai $\mathrm{MSE}<\max \mathrm{MSE}$ yang ditentukan atau jumlah epoch = nilai epoch yang ditentukan. Default nilai MSE adalah 0 , dan pelatihan ini menggunakan MSE $=0$. Nilai MSE yang didapatkan pada proses pelatihan terdapat pada Tabel 3 berikut ini.

Tabel 3 Nilai MSE Skenario

\begin{tabular}{ccc}
\hline No. & Skenario & MSE \\
\hline 1 & LR1 & 66.286 \\
2 & LR2 & 66.2565 \\
3 & LR3 & 65.2589 \\
4 & LR4 & 66.8746 \\
5 & E1 & 3.5116 \\
6 & E2 & 0.6476 \\
7 & E3 & 0.31099 \\
8 & E4 & 0.028944 \\
\hline
\end{tabular}

\section{PENUTUP}

\subsection{Kesimpulan}

Berdasarkan rumusan masalah dan penjelasan yang sudah penulis jelaskan pada bab sebelumnya, maka penulis membuat kesimpulan bahwa huruf hijaiyah khat kufi dapat dikenali polanya pada sistem dengan mengambil nilai matriks hasil deteksi tepi dan dilasi melalui teknik pengolahan citra dan jaringan syaraf tiruan dengan menggunakan algoritma backpropagation.

Alur proses secara keseluruahan terlebih dahulu dilakukan pra-proses citra, melakukan pembelajaran dengan jaringan syaraf tiruan dan melakukan pengenalan pola. Tahapan pra-proses citra yang dilakukan yaitu akuisisi citra, scaling dan grayscale, deteksi tepi, thresholding, dilasi dan selanjutnya matriks hasil dilasi disimpan di sebuah folder penyimpanan.

Pelatihan jaringan syaraf tiruan dengan algoritma backpropagation menggunakan 8 skenario pelatihan dengan paramater epoch 1000, 3000, 5000, dan 10000 serta learning rate $0.01,0.05,0.1,0.5$. Berdasarkan skenario pelatihan yang telah dilakukan didapatkan hasil maksimal pada skenario E4 (lihat Tabel 2) dengan tingkat akurasi $100 \%$.

\subsection{Saran}

Penulis menyarankan untuk nengembangkan penelitian ini agar menjadi lebih baik dengan melakukan beberapa hal seperti simulasi peneltian yang dilakukan tidak hanya berbasis dekstop, tapi juga smartphone. Pengenalan pola tidak hanya untuk mengenali huruf tapi juga karakter huruf dan output yang diberikan berupa suara. Penelitian ini dapat dikembangkan dengan melakukan pengenalan pola khat lain. Juga tidak hanya huruf tapi juga mengenali kata atau kalimat. Kemudian dapat pula menggunakan teknik pengenalan pola lainnya seperti PCA, JST LVQ, JST ADALAINE, serta deteksi tepi lain seperti canny, robert, dan prewitt.

\section{DAFTAR PUSTAKA}

[1] Sirojuddin, D. 2007. Seni Kaligrafi Islam. Jakarta: Multi Kreasi Singgasana.

[2] Siang, J.J. (2009). Jaringan Syaraf Tiruan dan Pemrograman Menggunakan Matlab. Yogyakarta: Andi.

[3] Putra, Darma. 2010. Pengolahan Citra Digital. Yogyakarta: Andi.

[4] Abed, Majida Ali dan Hamid Ali Abed Alasad. 2015. High Accuracy Arabic Handwritten Characters Recognition Using Error Back Propagation Artificial Neural Networks. University of Tikrit. Tikrit Iraq.

[5] Kanta, Imam Anggara. 2013. Pengenalan Pola Huruf Hijaiyah Tulisan Tangan Menggunakan Logika Fuzzy dengan Jaringan Syaraf Tiruan Backpropagation. Universitas Muhammadiyah Surakarta. Surakarta.

[6] Jas, Nurul Ainis. 2016. Identifikasi Jenis-jenis Kaligrafi Islam dengan Menggunakan Teknik Pengolahan Citra dan Jaringan Syaraf Tiruan Algoritma 
Backpropagation. UIN syarif Hidayatullah. Jakarta.

[7] Hara, Eliza. 2016. Pengenalan Tulisan Tangan Aksara Lampung dengan Metode Deteksi Tepi (Canny) Berbasis Jaringan Syaraf Tiruan Backpropagtion. Universitas Negeri Lampung. Lampung.

[8] Sutoyo, T. 2009. Teori Pengolahan Citra Digital. Yogyakarta: Andi.

[9] Widodo, P dkk. 2013. Penerapan Data Mining dengan Matlab. Bandung: Rekayasa Sains.

[10] Kakiay, T. 2004. Pengantar Sistem Simulasi. I. Yogyakarta: Andi. 